\title{
GERMINAÇÃO DE SEMENTES EM DESENVOLVIMENTO DE Bixa orellana
}

\author{
LOURDES ISABEL VELHO DO AMARAL ${ }^{1}$, MARIA DE FÁTIMA D. A. PEREIRA ${ }^{2}$ \\ E ÂNGELO LUIZ CORTELAZZO 3
}

Departamento de Botânica, Universidade de Brasília, Brasília/DF

\begin{abstract}
RESUMO - Com este trabalho objetivou-se investigar a aquisição da capacidade germinativa e o estabelecimento da dormência em sementes em desenvolvimento de Bixa orellana L. (urucum). Foram caracterizados 7 estádios de desenvolvimento das sementes, baseados nas características morfológicas, massa fresca, massa seca e teor de umidade dos frutos e das sementes. Sementes imaturas de B. orellana não germinaram durante os estádios iniciais de seu desenvolvimento. As sementes adquiriram a capacidade germinativa máxima quando os níveis de umidade declinaram para valores em torno de $60 \%$. Nessa fase, as sementes apresentaram acúmulo máximo de massa seca. A dormência foi estabelecida quando as sementes exibiam um conteúdo de água em torno de $10 \%$.
\end{abstract}

TERMOS ADICIONAIS PARA INDEXAÇÃO: Tegumento, dessecamento, dormência

\section{GERMINATION IN DEVELOPING SEEDS OF Bixa orellana}

\begin{abstract}
The objective of this work was to investigate the acquisition of germination capacity and the onset of dormancy in developing seeds of Bixa orellana L. (annatto). Seven stages of development were characterized with regard to morphology, fresh and dry mass and moisture content of the fruits and seeds. Immature seeds of $B$. orellana did not germinate during early stages of their development. The seeds achieved their maximum germination capacity after the moisture content had declined to around $60 \%$. In this phase the seeds presented maximum dry mass. The onset of dormancy occurred when the seeds exhibited water contents around $10 \%$.
\end{abstract}

ADDITIONAL INDEX TERMS: Desiccation, dormancy, tegmen

\section{INTRODUÇÃO}

Durante o seu desenvolvimento, a semente de uma angiosperma passa por três fases distintas: histodiferenciação ou morfogênese inicial, expansão celular concomitante à fase de acúmulo de reserva, e a fase final, que corresponde ao dessecamento (Thaker, 1999). O dessecamento constitui um evento integrante do processo do desenvolvimento da maioria das sementes, especialmente as ortodoxas (Kermode et al., 1986).

Recebido: 6/4/00 - Aceito: 13/10/00

1. Professora Assistente do Departamento de Botânica, Universidade de Brasília, ICC Sul - Campus Darcy Ribeiro - 70.910-900

- Caixa Postal 04467 - Brasília - DF e-mail: iamaral@unb.br

2. Professora Titular, Departamento de Fisiologia Vegetal, Universidade Estadual de Campinas, Campinas, SP

3. Professor Livre Docente, Departamento de Biologia Celular, Universidade Estadual de Campinas, SP 
Amaral et al.

Nesse grupo, o desenvolvimento só se completa quando a semente apresenta baixos teores de umidade. Possivelmente o dessecamento tem um papel fundamental na interrupção dos processos de desenvolvimento essenciais para a germinação, pois a reidratação de sementes quiescentes conduz à germinação (Bewley e Black, 1994).

Em muitas sementes, durante a fase de dessecamento, os tegumentos tornam-se impermeáveis à água. Esse tipo de dormência é bastante comum, principalmente em leguminosas arbóreas (Rolston, 1978). Assim, o conhecimento da ontogênese e das alterações sofridas pelos tegumentos durante o desenvolvimento das sementes assumem grande importância. Corner (1976) estabeleceu uma classificação para sementes baseada na origem dos tegumentos. Os tecidos que se originam a partir do tegumento externo denominam-se testa e aqueles que se desenvolvem do tegumento interno constituem o tégmen. Em muitas sementes, a testa é a principal responsável pela proteção dos tecidos internos, e o tégmen não apresenta nenhuma função mecânica, freqüentemente sofrendo compressão pelo endosperma e pelo embrião. Esse tipo é bastante comum nas leguminosas. Em outras espécies, o tégmen é o responsável pela proteção do embrião e de outros tecidos internos, e se a testa não desaparece, ela se especializa em outras funções, como a de secreção de corantes, como ocorre em Bixa orellana (Chopra e Kaur, 1965). Esses corantes são carotenóides identificados como bixina e norbixina (Reith, 1971). Assim, de acordo com o exposto acima, as sementes de Bixa orellana podem ser classificadas como tégmicas.

O objetivo dos autores deste trabalho foi estudar o processo de desenvolvimento das sementes de Bixa orellana (Bixaceae), com ênfase na capacidade germinativa e no estabelecimento da dormência. Para isso, foram realizadas análises de germinabilidade, bem alterações no aspecto estrutural do tégmen durante várias fases de desenvolvimento das sementes.

\section{MATERIAL E MÉTODOS}

O acompanhamento do desenvolvimento das sementes de Bixa orellana L. (urucum) foi feito a partir da antese, mediante a marcação das flores com etiquetas devidamente datadas. Os frutos foram coletados de plantas localizadas no Campus da Escola Superior de Agronomia Luiz de Queirós (ESALQ), em Piracicaba, São Paulo.

Para determinação dos estádios de desenvolvimento, foram retirados, a partir da antese, 10 frutos por coleta, em intervalos 15 dias. Nessas amostras, foram observadas características, como comprimento, forma, coloração, massa fresca e seca associadas ao teor de umidade dos frutos e sementes. Esses parâmetros foram utilizados para agrupar as sementes em estádios de desenvolvimento fisiológico sucessivos desde a sua formação até a maturação.

A massa fresca e seca de 100 sementes, em cada estádio de desenvolvimento, foi determinada em balança analítica. A massa seca das sementes, em cada estádio de desenvolvimento, foi determinada após secagem em estufa a $80^{\circ} \mathrm{C}$ por 48 horas. Foi também utilizado um método de secagem rápida, através de um dimer (regulador eletrônico de potência elétrica) acoplado a uma lâmpada de infravermelho, com intensidade constante, previamente padronizada, durante 90 minutos. Esse método de secagem rápida foi utilizado quando se tornou necessário obter caracterizações imediatas dos estádios de desenvolvimento, baseadas em massa seca e teor de umidade. O teor de umidade foi calculado com base na massa fresca e seca das sementes, a partir da relação:

Teor de umidade $=[($ massa fresca - massa seca $) /$ massa fresca].100

A absorção de água pelas sementes em desenvolvimento foi estimada através do aumento de massa fresca, após embebição por diferentes períodos, com base na massa fresca inicial determinada em balança analítica. As sementes foram pesadas em 4 grupos de 25 .

Para estudos de germinação, utilizaramse placas de Petri de $9 \mathrm{~cm}$ de diâmetro com duas 
folhas de papel de filtro umedecido, que foram esterilizadas em estufa a $105^{\circ} \mathrm{C}$ por 3 horas. As sementes foram colocadas para germinar nessas placas, contendo solução antifúngica de nistatina (100U.mL $L^{-1}$ ), para evitar ataque de fungos. As sementes foram mantidas em câmara de germinação sob luz contínua proveniente de 4 lâmpadas fluorescentes brancas $\left(320 \mu \mathrm{W} . \mathrm{cm}^{-2}\right)$ e temperatura constante de $25^{\circ} \mathrm{C}$. Para cada experimento foram utilizadas 4 repetições de 25 sementes.

A análise estatística foi feita utilizando-se a análise de variância simples, associada ao teste $F$ máximo de Hartley. Quando $F$ foi significativo, utilizou-se o teste de Tukey a 5\% (Pimentel Gomes, 1982). As diferenças significativas foram representadas nas figuras com barras verticais ou com letras diferentes. A velocidade de germinação e o tempo médio de germinação foram calculados de acordo com Labouriau (1983).

As sementes, nos diversos estádios de desenvolvimento, foram fixadas em FAA 50 (Johansen 1940) ou formol a 4\% (Lison, 1960) para análise microscópica do envoltório ou ainda em formaldeído a $4 \%$ e sulfato ferroso a $2 \%$ (SF) para detecção de taninos (Johansen, 1940). Após a fixação, as sementes foram desidratadas em álcool butílico terciário, permanecendo em álcool butílico a $70 \%$ por 3 meses. No restante do processo de desidratação, foram necessárias 48 horas de intervalo entre cada troca de álcool (Amaral et al., 1995). As sementes foram então incluídas em parafina e seccionadas em cortes transversais com $8 \mu \mathrm{m}$ de espessura. A desparafinização dos materiais foi feita utilizando-se xilol, álcool-xilol 1:1, metanol-clorofórmio $1: 1$, hidratação em álcool etílico em série decrescente de concentração (de 100 a 50\%) e água destilada (Johansen 1940). Os cortes foram então corados com safranina e azul de astra (SA), exceto para o estádio E1. Nesse estádio, não foi possível obter cortes corados com SA que mostrassem claramente as células secretoras de corante. Por isso, utilizamos neste trabalho, para $\mathrm{E} 1$, coloração com ferricianeto férrico (FF), após fixação em formol a 4\%. Nos outros estádios de desenvolvimento, esse método de coloração (FF) não foi eficiente para mostrar o padrão de espessamento do tégmen. Os resultados foram registrados por meio de fotomicrografias obtidas em fotomicroscópio marca Olympus.

\section{RESULTADOS}

Foram caracterizados 7 estádios de desenvolvimento das sementes com base nas características morfológicas, nos valores de massa fresca e seca associadas ao teor de umidade dos frutos e das sementes (Tabela 1). As sementes e os frutos não apresentaram variação significativa em relação ao comprimento entre os diversos estádios de desenvolvimento, com exceção dos frutos do estádio E1. A forma das sementes variou de obovóide nos 4 primeiros estádios a cuneiforme nos três últimos estádios, graças provavelmente ao processo de dessecamento e espessamento do tégmen. A coloração das sementes variou de vermelha-clara até vermelha-escura nos últimos estádios. A coloração do fruto variou de verde a marrom-escura (epicarpo) e de branca a marrom (endocarpo), mas a forma ovalada permaneceu constante durante todo $\mathrm{o}$ processo de desenvolvimento. $\mathrm{O}$ teor de umidade das sementes decresceu à medida que seu desenvolvimento aumentou, até apresentar um valor muito baixo no último estádio (E7), quando as sementes já estavam completamente maduras, os frutos secos e com deiscência. Analisando a massa fresca das sementes, observou-se que durante os 4 estádios iniciais foi ocorrendo um aumento gradual em consequiência da deposição de material estrutural e de reserva, especialmente no endosperma (Amaral, 1990), até atingir um máximo no estádio 4. A massa fresca das sementes foi baixa no E1 por causa do baixo conteúdo de material estrutural (membranas e paredes celulares) e de reserva (Amaral, 1990), embora o seu teor de umidade fosse alto (85\%). No estádio E4, as sementes ainda apresentavam um teor de umidade relativamente alto (64\%), embora o acúmulo de massa seca já tivesse atingido o máximo. A partir desse estádio (E4), houve uma redução na massa fresca, em consequiência do dessecamento gradual da semente, até atingir o mínimo em E7 $(10,4 \%)$. 
Amaral et al.

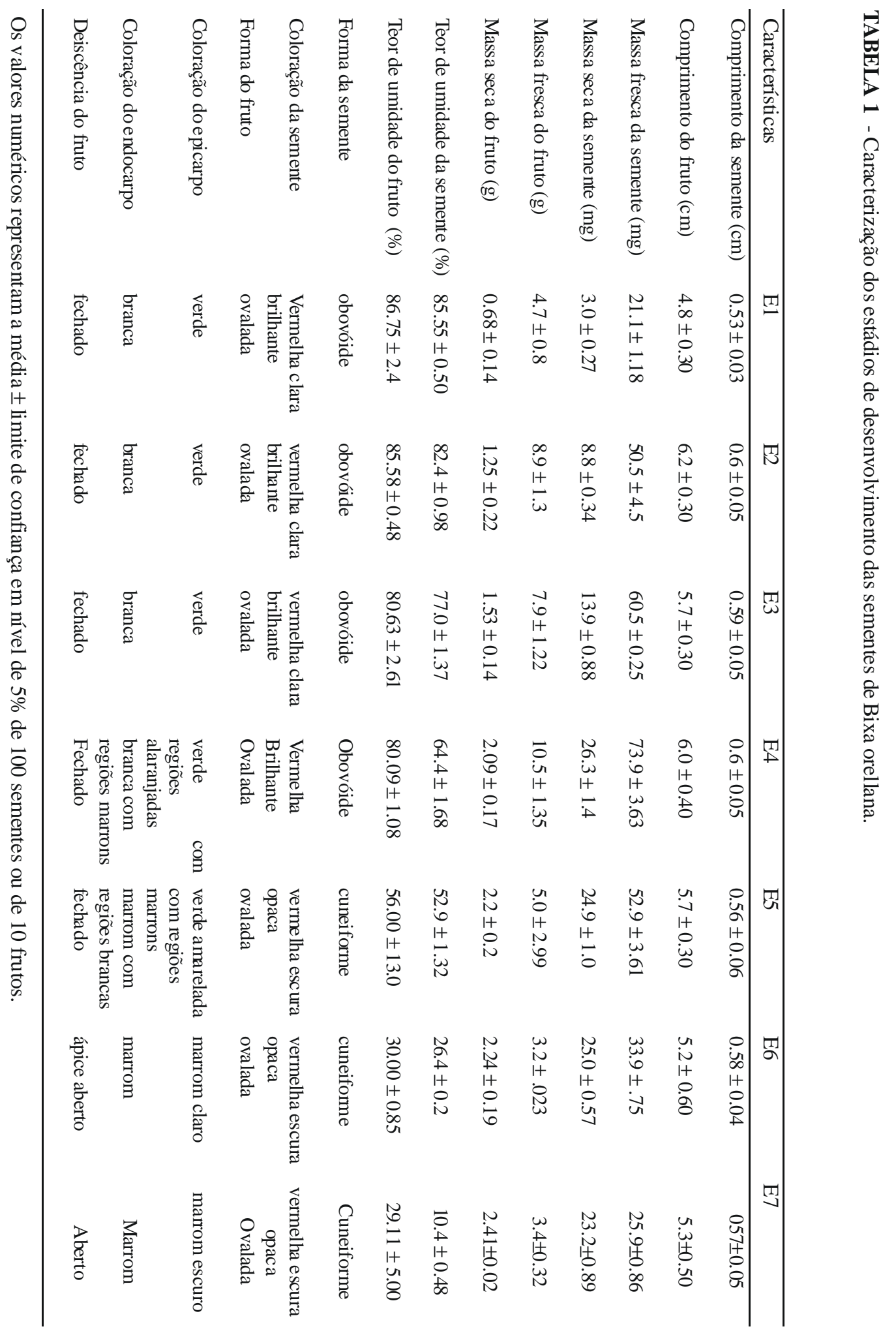

R. Bras. Fisiol. Veg., 12(3):273-285, 2000 
A análise da absorção de água pelas sementes em desenvolvimento foi feita durante 24 horas, (Figura 1). Observa-se que nos 3 primeiros estádios praticamente não ocorreu embebição. Nos estádios E4 e E5, a porcentagem de embebição foi significativamente maior em relação aos anteriores, mas não houve diferença estatística entre esses dois estádios de desenvolvimento. A partir do E6, a taxa de embebição começou a cair, e no último estádio (E7), os valores obtidos foram semelhantes aos encontrados no E3.

Após 16 dias de embebição, não ocorreu germinação nos 3 primeiros estádios de desenvolvimento, (Figura 2). As sementes passaram a germinar a partir do estádio $\mathrm{E} 4 \mathrm{e}$, neste estádio e no E5, a germinação atingiu o máximo. No estádio E6, a germinação foi inferior à quela apresentada nos estádios anteriores (E4 e E5), mas foi superior estatisticamente à do estádio E7, quando as sementes já estavam completamente maduras. Nesta última fase, a germinação foi muito baixa, pois o tégmen da maioria das sementes já estava completamente impermeável, impedindo a entrada de água nas sementes.

O tempo médio de germinação foi mais alto e a velocidade de germinação mais baixa no estádio E4, quando comparados com todos os outros estádios onde ocorreu germinação. Nos estádios anteriores, o tempo médio de germinação foi zero, pois não houve germinação. Nos estádios posteriores, não houve diferença significativa no tempo médio de germinação, embora a velocidade de germinação das sementes no E5 tenham sido menores do que nos estádios E6 e E7 (Tabela 2).

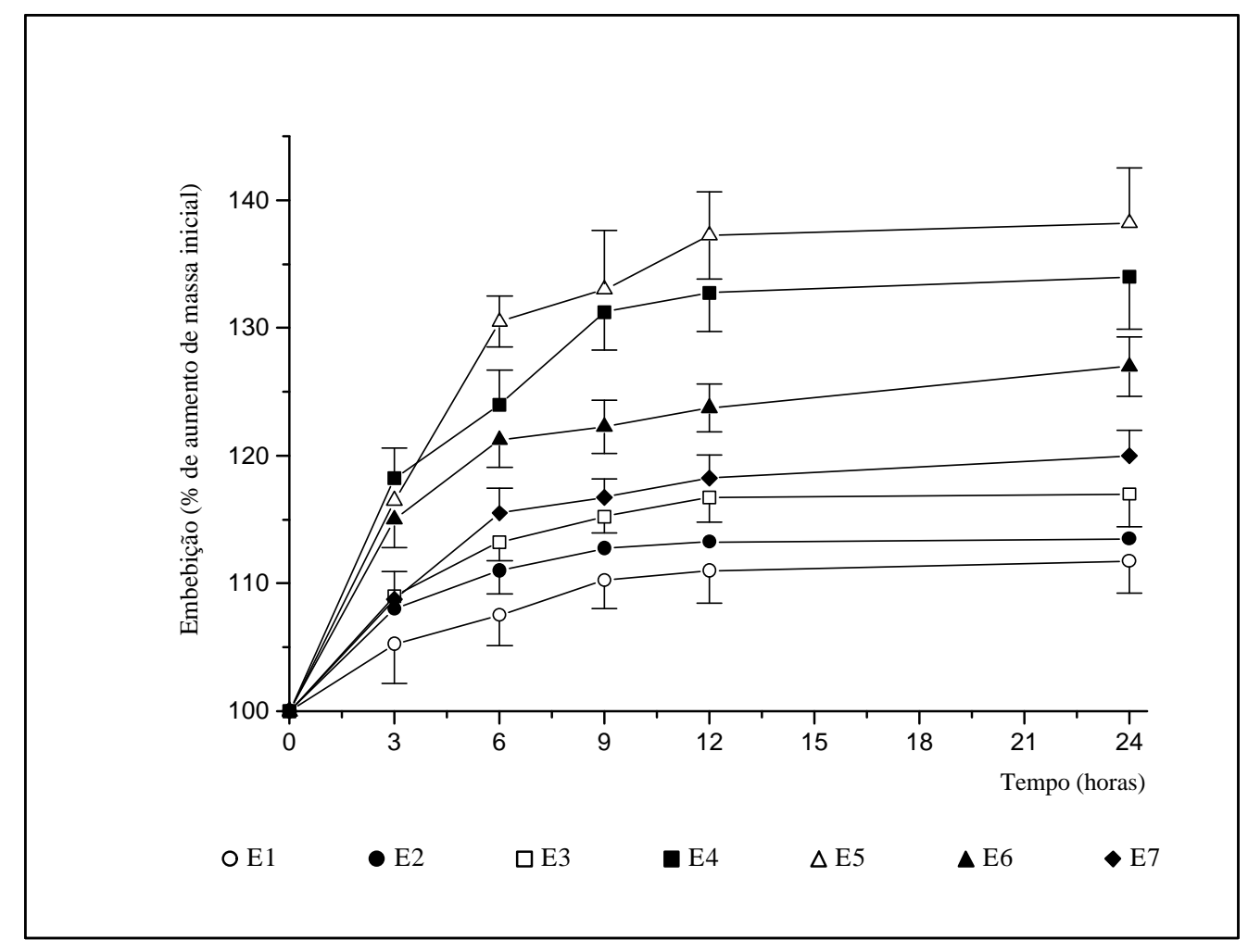

FIGURA 1 - Absorção de água por sementes em desenvolvimento de Bixa orellana, durante 24 horas, em porcentagem de aumento de massa em relação à massa fresca inicial. Barras verticais representam diferenças significativas a 5\%. As barras significam o desvio padrão da média. 


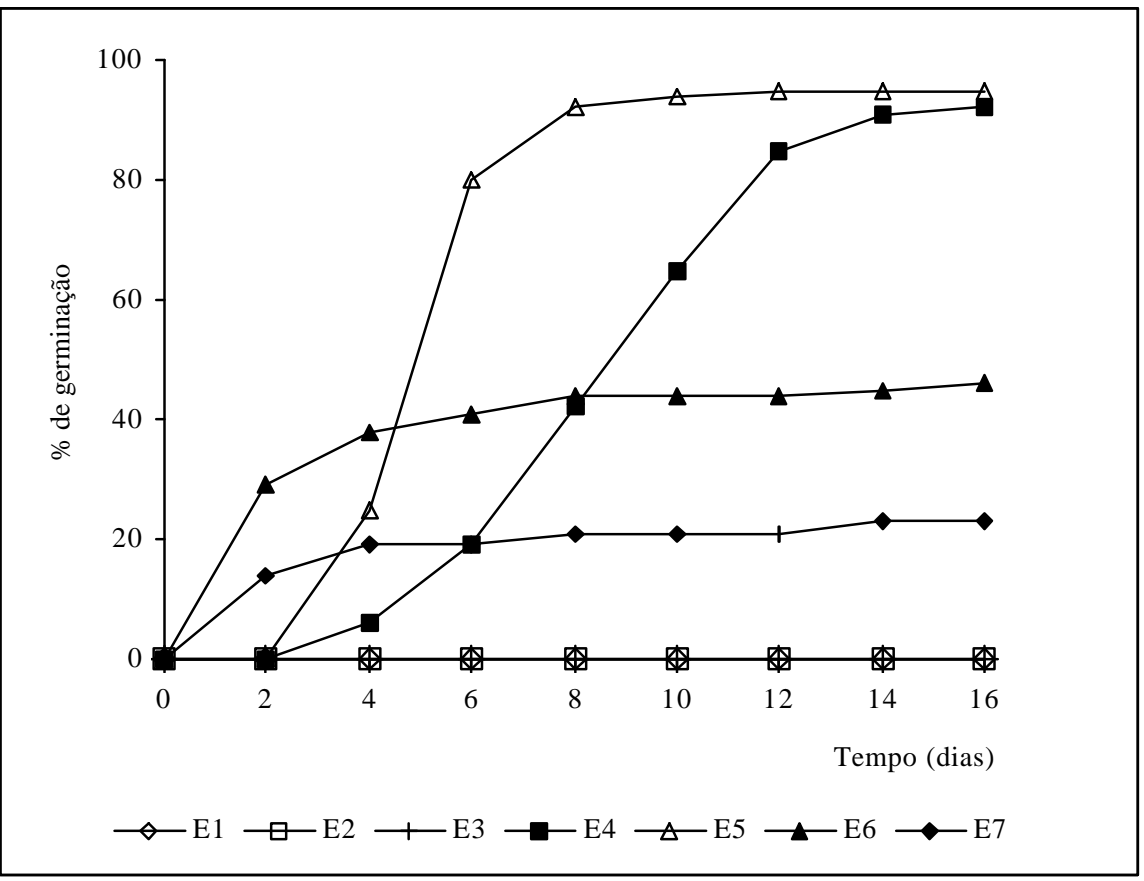

FIGURA 2 - Porcentagem de germinação de sementes em desenvolvimento de Bixa orellana, mantidas a $25^{\circ} \mathrm{C}$ e luz contínua. Letras diferentes representam diferenças significativas a $5 \%$, no último dia do experimento.

TABELA 2 - Tempo médio e velocidade de germinação de sementes de Bixa orellana nos diferentes estádios de desenvolvimento ( \pm desvio padrão).

\begin{tabular}{ccc}
\hline $\begin{array}{c}\text { Estádio de } \\
\text { Desenvolvimento }\end{array}$ & $\begin{array}{c}\text { Tempo médio de } \\
\text { Germinação (dias) }\end{array}$ & $\begin{array}{c}\text { Velocidade de } \\
\text { Germinação }\left(\operatorname{dias}^{-1}\right)\end{array}$ \\
\hline E1 & 0.0 & - \\
E2 & 0.0 & - \\
E3 & 0.0 & - \\
E4 & $8.43 \pm 0.47$ & $0.12 \pm 0.01$ \\
E5 & $3.81 \pm 0.28$ & $0.26 \pm 0.02$ \\
E6 & $3.09 \pm 0.55$ & $0.32 \pm 0.06$ \\
E7 & $3.05 \pm 0.34$ & $0.33 \pm 0.04$ \\
\hline
\end{tabular}


Verificou-se também um aumento gradual de massa seca à medida que as sementes em desenvolvimento se desidrataram, atingindo o máximo no estádio E4, embora o conteúdo de água ainda fosse alto (Figura 3). A redução maior do conteúdo de água ocorreu no estádio E7 (10,4\%), apesar de já ser baixo no estádio anterior, E6 $(26,4 \%)$. Verificou-se que a germinação ocorre a partir do momento em que o acúmulo de massa seca é máximo e ainda existe uma quantidade relativamente alta de água na semente. A germinação é mais baixa no estádio E6 e menor ainda no estádio E7, quando os teores de umidade são baixos e o acúmulo de massa seca está estável. Neste estádio (E7), a baixa germinação pode ser explicada pela impermeabilização do tégmen, pois na ausência de água o processo de germinação não é iniciado.

A testa das sementes de Bixa orellana, especializada na secreção de carotenóides (bixina e norbixina), está presente e funcional no estádio E1, conforme o evidenciado com ferricianeto férrico (FF). O tégmen apresenta a camada paliçádica pouco corada, ainda em formação (Figura 4). As células são mais largas na porção basal e apical em relação à s paredes laterais. Os osteosclereídeos já estão formados, mas ainda não espessados. Foi notada a presença de material corado logo abaixo da camada paliçádica, provavelmente taninos. O teste específico para taninos, sulfato ferroso (SF), comprovou a natureza química desse material (Figura 5). Esses taninos estão presentes também abaixo da camada de osteosclereídeos (Figura 6). No estádio seguinte, E2 (Figura 6), o tegumento externo começa a se desorganizar e as células secretoras dos carotenóides rompem, liberando o pigmento que permanece cobrindo o tégmen. Neste estádio (E2), as células do tégmen já se encontram completamente diferenciadas, especialmente ao nível da camada paliçádica. A partir do E2, vai

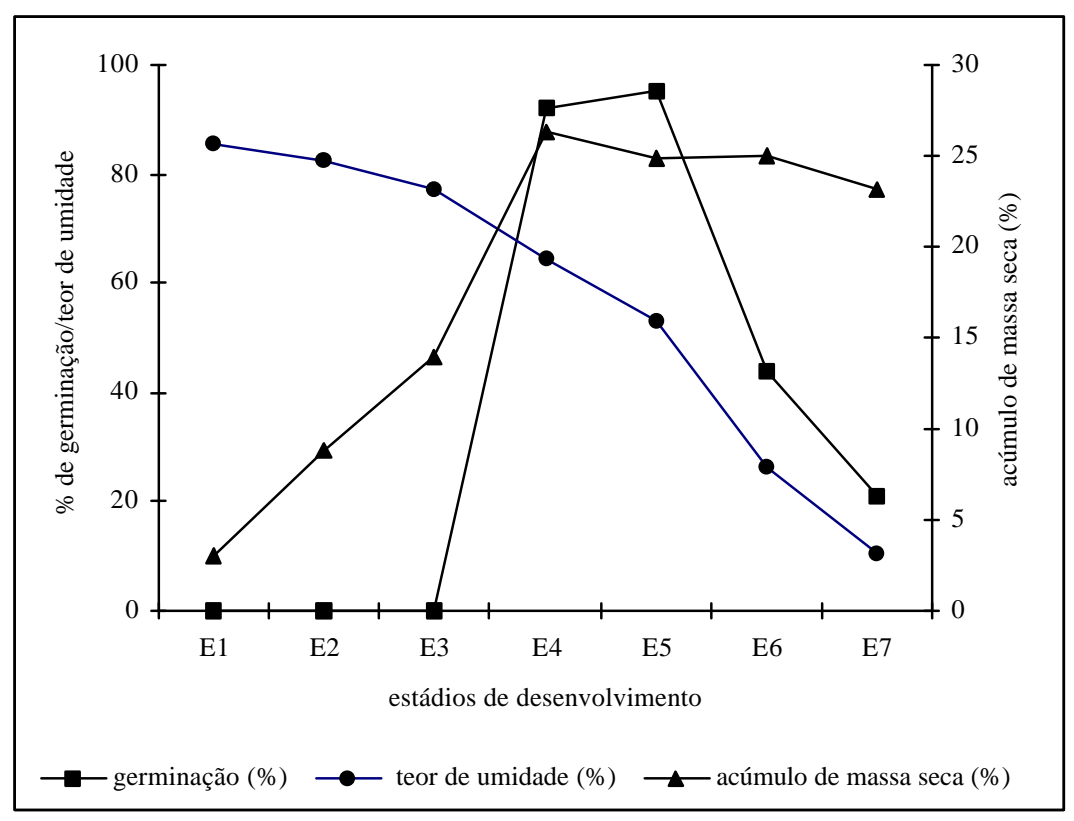

FIGURA 3 - Relação entre a porcentagem de germinação, porcentagem de acúmulo de massa seca e teor de umidade em sementes em desenvolvimento de Bixa orellana. 


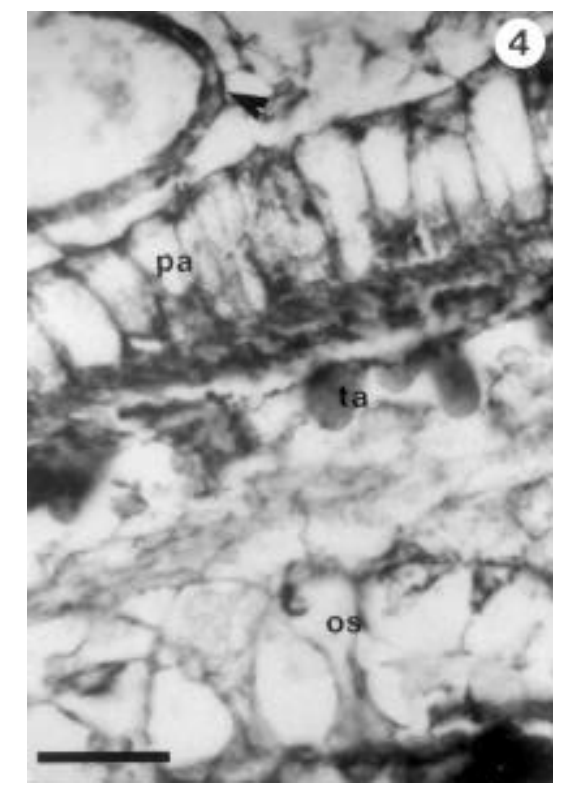

FIGURA 4 - Corte transversal da semente de Bixa orellana no estádio E1, corado com FF, evidenciando o tegumento externo com célula secretora de corante (seta), parênquima paliçádico em formação (pa), taninos (ta) e osteosclereídeos (os). Escala $=45 \mu \mathrm{m}$.

ocorrendo um espessamento ao nível das células paliçádicas e uma compressão em todas as camadas abaixo das mesmas. As células da paliçada apresentam-se mais longas do que largas, sendo mais largas na região basal do que na distal, apresentando nessa porção a extremidade acuminada ou ligeiramente arredondada. À medida que a semente se desenvolve em direção à maturidade, nota-se um aumento de substâncias que apresentam reação fortemente positiva a safranina nas células paliçádicas. Essas substâncias conferem uma maior rigidez ao tégmen, que se apresenta cada vez mais resistente ao corte com micrótomo, provocando ruptura da camada

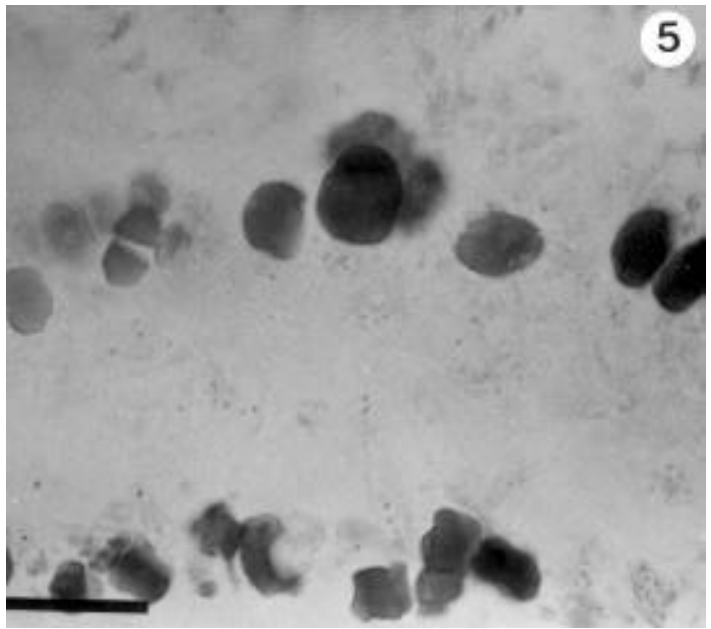

FIGURA 5 - Corte transversal da semente de Bixa orellana no estádio E1, corado com SF, evidenciando os taninos. Escala $=45 \mu \mathrm{m}$.

parenquimática e dos osteosclereídeos, nos estádios mais avançados (Figura 6-9).

\section{DISCUSSÃO}

A idade fisiológica das sementes pode ser caracterizada adequadamente por meio de alterações que ocorrem durante seu desenvolvimento. Essas alterações podem caracterizar índices de idade fisiológica, que são extremamente úteis, principalmente em condições naturais, em que a idade cronológica assume um significado menor por causa de alterações ambientais. 


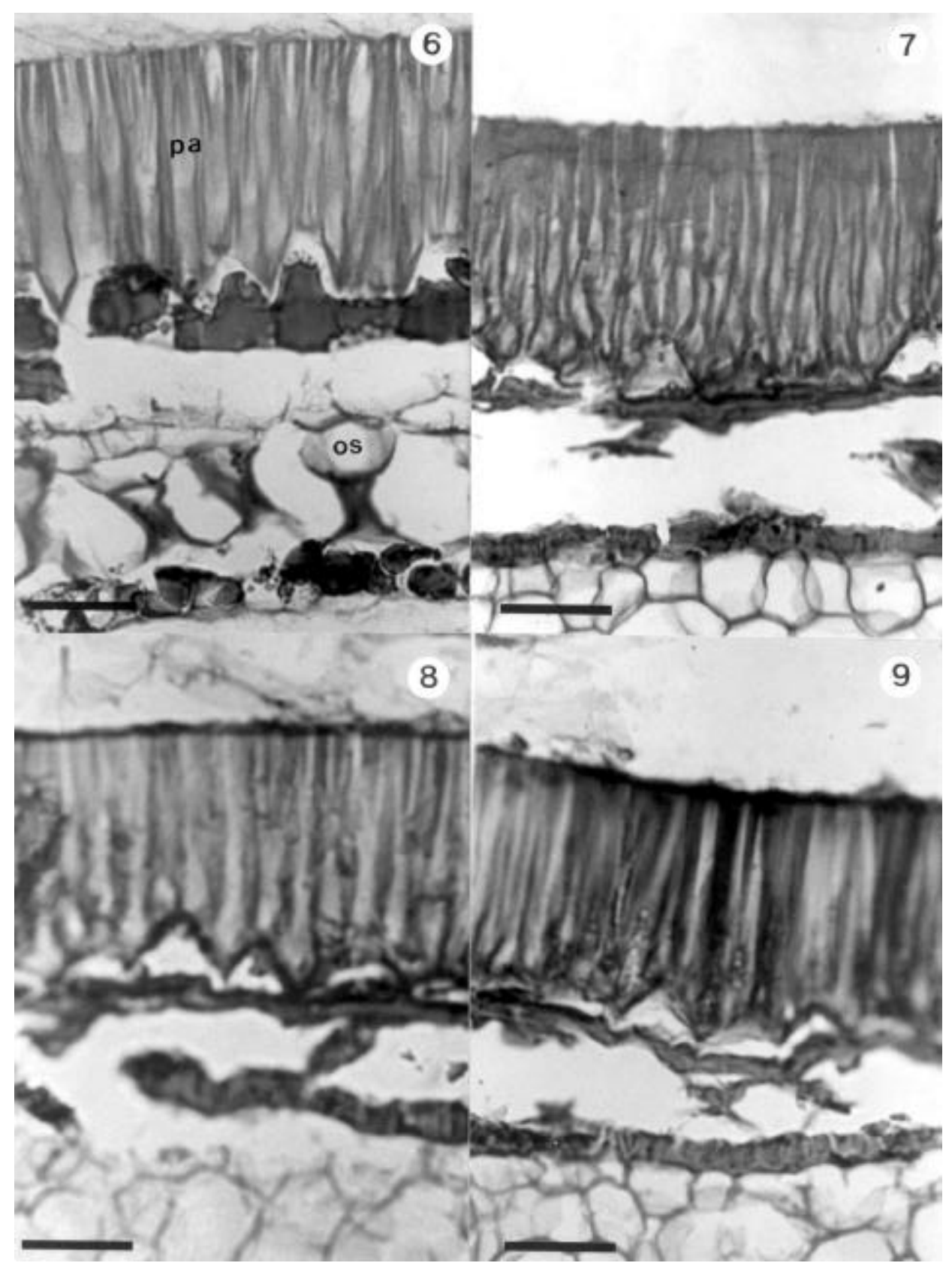

FIGURAS 6 - 9 - Cortes transversais do tégmen de sementes em desenvolvimento de Bixa orellana, corados com SA. 6: E2. Camada paliçádica (pa) totalmente formada, ainda não espessada e osteosclereídeos (os) em processo de espessamento. 7: E4. Camada paliçádica em processo de espessamento. 8: E5. Camada paliçádica espessada. 9. E7. Camada paliçádica apresentando um alto grau de espessamento. Nota-se um osteosclereídeo preservado. Escalas $=45 \mu \mathrm{m}$. 
Índices de idade fisiológica, baseados na morfologia e no comprimento de frutos e sementes, foram utilizados para caracterizar estádios de desenvolvimento de sementes (Adams e Rinne, 1981; Figueiredo e Pereira, 1985). Índices de idade fisiológica, baseados na massa fresca e teor de umidade, foram usados em Acacia auriculiformis (Pukittayacamee e Hellum, 1988). Em Bixa orellana, os estádios de desenvolvimento foram caracterizados com base tanto nas características morfológicas dos frutos e das sementes, bem como na massa fresca e seca, associadas com o teor de umidade. Entre esses parâmetros, a massa fresca e seca, associada com o teor de umidade das sementes, foram os mais adequados para separar todos os estádios de desenvolvimento. Entretanto, os parâmetros morfológicos foram convenientes para uma separação preliminar dos estádios de desenvolvimento.

A curva de embebição típica das sementes maduras normalmente apresenta três fases distintas, a saber: uma fase de rápida absorção, uma fase de estabilização, em que praticamente não há entrada de água na semente e uma terceira fase, em que a semente volta a apresentar um rápido aumento na massa fresca, como conseqüência da germinação (Metivier, 1985). Para sementes em desenvolvimento, esse padrão pode ser alterado sensivelmente. A análise da absorção de água pelas sementes imaturas de Bixa orellana mostrou um padrão diferente daquele discutido anteriormente. Sementes imaturas não embebem nos primeiros estádios de desenvolvimento, provavelmente por apresentarem altos níveis de hidratação (entre 77 e $85 \%$ ), uma vez que os tegumentos ainda estão completamente permeáveis, conforme pode ser observado pelas colorações com SA ou FF. Além disso, o endosperma das sementes possui poucas matrizes (proteínas e paredes celulares) que poderiam ter papel na alteração de seu potencial matricial (Amaral, 1990). À medida que a semente se desenvolve, há uma tendência a maior embebição, por causa de uma redução do potencial hídrico. A baixa embebição verificada no último estádio de desenvolvimento (E7) deve-se a um alto grau de impermeabilização e rigidez do tégmen, como foi verificado pela análise anatômica.

Nos estádios E4 e E5, há uma maior entrada de água em relação aos estádios anteriores, provavelmente por causa da presença de uma maior quantidade de matrizes hidrofílicas, como proteínas e paredes celulares, embora essas sementes ainda se encontrem com níveis de hidratação em torno de 60 e $50 \%$, respectivamente. Essa hidratação explicaria porque a taxa de embebição é mais baixa (130\% no E4 e $135 \%$ no E5) do que aquela obtida em sementes completamente maduras, escarificadas, que atingem cerca de $150 \%$ de embebição (Amaral et al., 1995). Além disso, no E5, o tégmen apresenta uma menor deposição de material que reage positivamente à safranina, se comparada com os estádios finais, indicando que o processo de impermeabilização está ocorrendo, mas ainda não está suficientemente estabelecido a ponto de impedir a entrada de água.

As sementes no estádio E6 apresentam um teor de umidade muito baixo, ao redor de $25 \%$, e também um adiantado processo de impermeabilização do tégmen (Amaral, 1990), o que explicaria a sua pouca embebição.

Entre todos os tecidos da semente, o envoltório (testa ou tégmen) é a estrutura que opõe maior resistência ao fluxo de água, como já foi demonstrado em sementes de colza (Brassica napus) (Shaykewi e Williams, 1971). Em sementes completamente maduras e impermeáveis de Bixa orellana, essa resistência é quase total (Amaral et al., 1995).

Sementes imaturas de urucum não germinaram durante os três primeiros estádios de desenvolvimento, em virtude provavelmente da insuficiência de materiais de reserva, como foi proposto para Phaseolus vulgaris cv. Goiano Precoce (Figueiredo, 1984). A capacidade germinativa foi atingida quando as sementes alcançaram o ponto de máximo acúmulo de massa seca. Essa fase foi alcançada quando as sementes ainda possuíam altos teores de umidade, confirmando o que foi encontrado para outras espécies, como, por exemplo, mamona (Ricinus communis) (Kermode e Bewley, 1989), couve-chinesa (Brassica rapa) (Ren e Bewley, 
1999) e feijão (Phaseolus vulgaris) (Adams e Rinne, 1981).

O teor de umidade nas sementes de Bixa orellana declinou durante o período sobre o qual a germinabilidade se desenvolveu. A principal mudança no conteúdo de água coincidiu com o máximo acúmulo de massa seca. É possível que essa perda de água tenha algum papel no desenvolvimento da capacidade germinativa, ou no gradiente de potencial hídrico entre a semente e o fruto (Welbaum e Bradford, 1989).

Além disso, os períodos de intensa desidratação que aparentemente são importantes para o desenvolvimento de sementes de leguminosas ocorrem após o acúmulo de massa seca, como verificado em ervilha (Pisum sativum) (Le Deunff e Rachidian, 1988) e soja (Glycine max) (Rosenberg e Rinne, 1986). Em melão (Cucumis melo), a taxa de declínio em conteúdo de água é mais lenta após a fase final de acúmulo de massa seca (Welbaum e Bradford, 1989). Entretanto, em B. orellana, ocorre inicialmente uma perda muito lenta de água (E1-E3). Essa perda de água ainda é lenta quando a semente atinge o seu conteúdo máximo de massa seca (E4-E5) e, a partir desse ponto, cai bruscamente.

A velocidade de germinação que as sementes de urucum, no estádio E4, apresentam, é menor quando comparada com os estádios mais avançados, e nesses últimos (E6 e E7) a velocidade de germinação é praticamente idêntica. Em sementes de feijão, constatou-se que existem três faixas de velocidade de germinação das sementes durante o desenvolvimento, sendo maior no último estádio (Figueiredo e Pereira 1991). Esses autores demonstraram que a desidratação artificial conduz à promoção da capacidade e velocidade de germinação.

Embora períodos de intensa desidratação sejam importantes no processo de desenvolvimento das sementes, períodos de redução mais sutil no conteúdo de água são igualmente importantes, pois agem como um sinal ao estabelecimento da tolerância ao dessecamento. Em trigo, uma perda incipiente do seu conteúdo hídrico induz o aparecimento de deidrinas que promovem alterações metabólicas que capacitam a semente a se tornar tolerante ao dessecamento (Black et al. 1999).

A proposição de que a desidratação impõe o processo de maturação nas sementes (Adams e Rinne, 1981, Rosenberg e Rinne, 1986) poderia explicar este atraso na germinação das sementes de B. orellana no estádio E4. Entre os estádios E4 e E5 poderiam ocorrer mudanças sutis resultantes de pequenas flutuações no conteúdo de água, que por sua vez afetariam a velocidade de germinação. Estas flutuações de conteúdo de água à medida que ocorre a desidratação, causam alterações no metabolismo em sementes de soja (Rosenberg e Rinne, 1986), bem como alterações quantitativas e qualitativas de RNAm em sementes de Ricinus comunnis (Kermode et al. 1989a). Também foram observadas alterações no balanço hormonal (níveis de ABA), inibindo ou permitindo o desenvolvimento até a germinação em sementes de Ricinus communis (Kermode et al., 1989b), embora tenha sido demonstrado na cultivar Goiano Precoce de Phaseolus vulgaris que o nível endógeno de ABA não está relacionado com a capacidade germinativa das sementes em desenvolvimento (Figueiredo e Pereira, 1991).

\section{REFERÊNCIAS}

ADAMS, C. A. \& RINNE, R. W. Seed maturation in soybeans (Glycine $\max$ L. merr.) is dependent of seed mass and the parent plant, yet is necessary for production of viable seeds. Journal of Experimental Botany, 32: 615620, 1981.

AMARAL, L. I. V. Germinação e dormência em sementes em desenvolvimento de Bixa orellana L.: aspectos fisiológicos e estruturais. Campinas, Universidade Estadual de Campinas, 1990. 122 p. Tese de Mestrado.

AMARAL, L.I.V.; PEREIRA, M.F.A. \& CORTELAZZO, A. .L. Quebra da dormência em sementes de Bixa orandllana. Revista Brasileira de Fisiologia Vegetal, 7: 151-157, 1995. 
BEWLEY, J. D. \& BLACK, M. Seeds. Physiology of development and germination. 2 ed, New York, Plenum Press, 1994. 445 p.

BLACK, M.; CORBINEAU, F., GEE, H. \& COME, D. Water content, raffinose and dehydrins in the induction of desiccation tolerance in immature wheat embryos. Plant Physiology, 120: 463-471, 1999.

CHOPRA, R. N. \& KAUR, H. Embryology of Bixa orellana Linn. Phytomorphology, 15: 211-215, 1965.

CORNER, E. J. H. The seeds of dicotyledons. Cambridge, Cambridge University Press. 1976. v.2.

FIGUEIREDO, P. S. Germinação de sementes imaturas de Phaseolus vulgaris L. cv. Goiano Precoce. Campinas, Universidade Estadual de Campinas, 1984. 103p. Tese de Mestrado.

FIGUEIREDO, P. S. \& PEREIRA, M. F. A. Immature seeds of Phaseolus vulgaris L.: development, germination and reproductive capacity of the resulting plants. Revista Brasileira de Botânica, 8:169-175, 1985.

FIGUEIREDO, P. S. \& PEREIRA, M. F. A. Germinação de sementes imaturas de Phaseolus vulgaris: envolvimento do ácido abscísico. Revista Brasileira de Botânica, 14: 83-88, 1991.

JOHANSEN, D. A. Plant microtechnique. New York, McGaw, 1940. 523p.

KERMODE, A. R.; BEWLEY, J. D.; DASGUPTA, J. \& MISRA, S. The transition from seed development to germination: a key role for desiccation? HortScience, 21:1113$1118,1986$.

KERMODE, A. R. \& BEWLEY, J. D. Development seeds of Ricinus communis L., when detached and maintained in an atmosphere of high relative humidity, switch to a germinative mode without the requirement for complete desiccation. Plant Physiology, 90: 702-707, 1989.
KERMODE, A. R., PRAMANIK, S. K. \& BEWLEY, J. D. The role of maturation drying in the transition from seed development to germination. VI-Desiccation-induced changes in messenger RNA populations within the endosperm of Ricinus communis L. seeds. Journal of Experimental Botany, 40:33-41, 1989a.

KERMODE, A. R., DUMBROFF, E. B \& BEWLEY, J. D. The role of maturation drying in the transition from seed development to germination. VII-Effects of partial and complete desiccation on abscisic acid levels and sensivity in Ricinus communis L. seeds. Journal of Experimental Botany, 40:303$311,1989 b$.

LABOURIAU, L. G. A germinação das sementes. Washington, Organização dos Estados Americanos, 1983. 174p.

LE DEUNFF, Y. \& RACHIDIAN, Z. Interruption of water delivery at physiological maturity is essential for seed development germination and seedling growth in pea (Pisum sativum L.) Journal of Experimental Botany, 39:12211230, 1988.

LISON, L. Histochemie et citochemie animales. Paris, Gauthier-Villars, 1960. 607p.

METIVIER, J. R. Dormência e germinação. In: FERRI, M. G (Coord.). Fisiologia vegetal. 2 ed. EPU, São Paulo. 1986. v.2. 401p.

PIMENTEL GOMES, F. Curso de estatística experimental. São Paulo, Nobel, 1982. 430p.

PUKITTAYACAMEE, P. \& HELlUM, A. K. Seed germination in Acacia auriculiformis: developmental aspects. Canadian Journal of Botany, 66: 388-393, 1988.

REITH, J. F. Properties of bixin and norbixin and the composition of annatto extracts. Journal of Food Science, 36: 861-864, 1971. 
REN, C. W. \& BEWLEY, J. D. Developmental and germinative events can occur concurrently in precociously germinating Chinese cabbage (Brassica rapa ssp Pekinensis) seeds. Journal of Experimental Botany, 50: 1751-1761, 1999.

ROLSTON,M.P.Water impermeable seed dormancy. Botanical Review, 44: 365-396, 1978.

ROSENBERG, L. A. \& RINNE, R. W. Moisture loss as a prerequisite for seedling growth in soybean seeds (Glycine max L. merr.). Journal of Experimental Botany, 37:1663-1674, 1986.
SHAYKEWI, C. F. \& WILLIAMS, J. Resistance to water absorption in germinating rapeseed (Brassica napus L.). Journal of Experimental Botany, 22: 19-24, 1971.

THAKER, V. Changes in water content, sugars and invertase activity in developing seeds of Hibiscus esculentum. Acta Physiologiae Plantarum, 21: 155-159, 1999.

WELBAUM, G. E \& BRADFORD, K. J. Water relations of seed development and germination in muskmelon (Cucumis melo L.). Journal of Experimental Botany, 40:1355-1362, 1989. 